\title{
DINUCLEAR METAL COMPLEXES DERIVED FROM A BIS-CHELATING HETEROCYCLIC LIGAND
}

\author{
Worku Assefa, V.J.T. Raju, Yonas Chebude* and Negussie Retta
}

Department of Chemistry, Addis Ababa University, P.O. Box 1176, Addis Ababa, Ethiopia

(Received March 4, 2008; revised February 19, 2009)

\begin{abstract}
C}_{16} \mathrm{H}_{12} \mathrm{~N}_{10} \mathrm{O}_{2} \mathrm{Cl}_{4}$ ( $\left.\mathrm{H}_{2}-\mathrm{BDTD}\right)$, and $\mathrm{Co}$ (II), $\mathrm{Ni}$ (II), $\mathrm{Cu}$ (II) and $\mathrm{Zn}$ (II) complexes derived from its dibasic bis-chelating form (BDTD ${ }^{2-}$ or $\mathrm{L}^{2-}$ ) were prepared in methanol-triethylamine and characterized by MS, NMR, IR, UV-VIS and AA spectroscopic studies. Conductivities, magnetic susceptibility measurements and thermal analyses showed bis$\mathrm{N}, \mathrm{N}, \mathrm{O}$ donor behavior of $\mathrm{L}^{2-}$. The analytical data indicate that the metal to ligand ratio is $2: 1$ in all the complexes. The coordination of triethylamine, water and chloride ion are observed in the $\mathrm{Co}$ (II), $\mathrm{Zn}$ (II) and Ni(II) complexes. The absence of ionizable or coordinated chloride in $\mathrm{Cu}$ (II) complex is a notable feature. Octahedral geometry for $\mathrm{Co}(\mathrm{II}), \mathrm{Zn}$ (II) and $\mathrm{Ni}$ (II) and square planar geometry for $\mathrm{Cu}(\mathrm{II})$ complexes are proposed. The paramagnetic complexes exhibit subnormal magnetic moments at room temperature (RT).
\end{abstract}

KEY WORDS: Bimetallic complexes, Multidentate ligand, Triazine, Subnormal magnetic moments

\section{INTRODUCTION}

A wide variety of heterocycles containing azomethine centers, which vary in denticity, flexibility, nature of donor atoms and electronic properties, have been studied for use in pharmaceuticals, pesticides, dyestuffs, polymers and in several other biochemicals [1-4]. Metal complexes containing 1,3,5-triazine functions are used in electronic, photomolecular, magnetic, and supramolecular devices [5-10] and are also applied in biocoordination chemistry [11, 12]. However, literature survey reveals that metal complexes of heterocyclics like 1,3,5,-triazines, substituted on aromatic rings have not been well studied. The present investigation is aimed at the synthesis and characterization of first row transition metal complexes derived from a multidentate system having an aromatic backbone containing triazine and hydroxyl substitutents. Prior to the synthesis of one such new system $\mathrm{H}_{2}$-BDTD, $\left(\mathrm{C}_{16} \mathrm{H}_{12} \mathrm{~N}_{10} \mathrm{O}_{2} \mathrm{Cl}_{4}\right)$, the precursor compounds such as 2,4-dihydroxy-5-acetylacetophenone (DAAP), 2,4-dihydroxy-5acetylacetophenone dihydrazone (DAAD) were prepared following earlier reports [11, 13]. Their ${ }^{1} \mathrm{H}$ and ${ }^{13} \mathrm{C}$ NMR data are reported in this communication.

\section{Chemicals}

\section{EXPERIMENTAL}

All chemicals used in the investigation were of AnalaR grade. The solvents were purified by standard procedures. Cyanuric chloride, resorcinol, $\mathrm{ZnCl}_{2}$, acetic anhydride and $\mathrm{N}_{2} \mathrm{H}_{4} \cdot \mathrm{H}_{2} \mathrm{O}(80$ $\%$ solution, density $0.8 \mathrm{~kg} \mathrm{~L}^{-1}$ ) were obtained from Aldrich. The solvents used were: $\mathrm{MeOH}$, $\mathrm{EtOH}, \mathrm{Et}_{3} \mathrm{~N}, \mathrm{Et}_{2} \mathrm{O}$, thf, dmso, all obtained from Riedel-de Haen.

\section{Instrumentation}

IR spectra were recorded on a Perkin Elmer Spectrum BX FT-IR spectrometer $\left(4000-400 \mathrm{~cm}^{-1}\right)$ in $\mathrm{KBr}$ medium. Electronic spectra were recorded on a Perkin Elmer Lambda 19 U.V.-VIS-NIR spectrometer (with a reflectance facility) using Nujol mulls. The ${ }^{1} \mathrm{H}$ NMR and ${ }^{13} \mathrm{C}$ NMR data

*Corresponding author. E-mail: yonasch@chem.aau.edu.et 
were collected by use of a Bruker 400 Ultra-Shield NMR instrument (400 and $100.6 \mathrm{MHz}$ for ${ }^{1} \mathrm{H}$ and ${ }^{13} \mathrm{C}$, respectively). Dmso- $\mathrm{d}_{6}$ was used as a solvent. The solid state NMR $\left({ }^{13} \mathrm{C}\right)$ of $\mathrm{H}_{2}$-BDTD was recorded on a Bruker $850 \mathrm{MHz}$ instrument at the School of Chemistry, University of Nottingham, UK. Thermal studies were conducted using a simultaneous DSC-TGA analyzer (SDT Q600, TA Instruments). Magnetic susceptibility measurements of the complexes in the solid state and at room temperature were made by use of a magnetic susceptibility balance (Sherwood Scientific), calibrated by $\mathrm{Hg}\left[\mathrm{Co}(\mathrm{SCN})_{4}\right]$. M.p./dec.pts. were determined on Electrothermal IA 9200, Digital Melting Point Apparatus and elemental analyses were undertaken using a Flash EA 1112 Elemental Analyzer (Thermo Quest). Conductivities were recorded at room temperature using $1 \times 10^{-3} \mathrm{M}$ solutions in $o$-dichlorobenzene by use of EC 214 Conductivity Meter (Hanna Instruments). Metal contents of the complexes were determined by Flame Atomic Absorption Spectrophotometry (Buck Model Scientific 210 VGP) after digesting a known amount of each sample in a $1: 1(\mathrm{v} / \mathrm{v}) \mathrm{HNO}_{3} / \mathrm{HClO}_{4}$. Chloride contents were determined argentometrically, after completely decomposing the complexes in nitric acid. The reported chloride percentage data will correspond with the total chloride in each compound, i.e. the chloride on triazine and ionic chloride. The mass spectrum and solid-state ${ }^{13} \mathrm{C}$ NMR of $\mathrm{H}_{2}-$ BDTD were obtained from the Indian Institute of Chemical Technology, Hyderabad, India and The School of Chemistry, University of Nottingham, UK, respectively.

Syntheses

2,4-Dihydroxy-5-acetylacetophenone (DAAP) [11, 13] (Scheme 1). ${ }^{1} \mathrm{H}$ NMR $\left(\mathrm{dmso}_{6}\right) \delta: 2.6$ (s, $\left.\mathrm{CH}_{3}\right) ; 8.2\left(\mathrm{~s}, \mathrm{H}_{\mathrm{a}}\right) ; 6.4\left(\mathrm{~s}, \mathrm{H}_{\mathrm{b}}\right) 12.9(\mathrm{~s}, \mathrm{OH}) ;{ }^{13} \mathrm{C} \mathrm{NMR}\left(\mathrm{dmso}_{6}\right) \delta: 136\left(\mathrm{C}_{\mathrm{a}}\right) ; 105\left(\mathrm{C}_{\mathrm{b}}\right) ; 26.3\left(\mathrm{C}_{1,1}\right)$; $202\left(\mathrm{C}_{2,2}\right) ; 114\left(\mathrm{C}_{3,3}\right) ; 169\left(\mathrm{C}_{4,4^{4}}\right)$. Yield $=60 \%$.

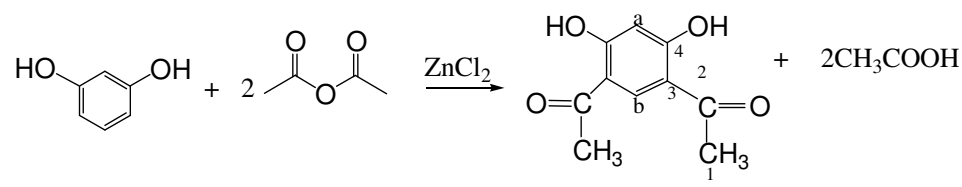

Resorcinol acetic anhydride

DAAP

Scheme 1. Synthesis of DAAP.

2,4-Dihydroxy-5-acetylacetophenone dihydrazone (DAAD) (Scheme 2). ${ }^{1} \mathrm{H}$ NMR (dmso- $\left.\mathrm{d}_{6}\right)$ $\delta: 6.2\left(\mathrm{~s}, \mathrm{NH}_{2}\right) ; 2.1\left(\mathrm{~s}, \mathrm{CH}_{3}\right), 7.3\left(\mathrm{~s}, \mathrm{H}_{\mathrm{a}}\right), 6.1\left(\mathrm{~s}, \mathrm{H}_{\mathrm{b}}\right) 13.6(\mathrm{~s}, \mathrm{OH}) ;{ }^{13} \mathrm{C} \mathrm{NMR}\left(\mathrm{dmso}_{6}\right): \delta 120.0$ $\left(\mathrm{C}_{1,1}\right), 113.14\left(\mathrm{C}_{2,2^{\prime}}\right), 150.86\left(\mathrm{C}_{3,3^{\prime}}\right), 160.46\left(\mathrm{C}_{4,4^{\prime}}\right), 125.78\left(\mathrm{C}_{\mathrm{a}}\right), 104.32\left(\mathrm{C}_{\mathrm{b}}\right)$. Yield $=80 \%$.

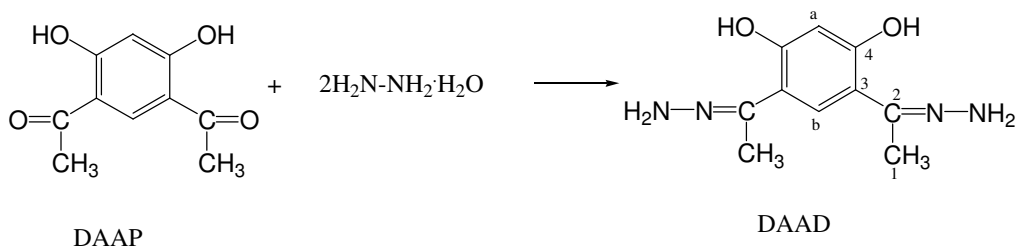

Scheme 2. Synthesis of DAAD.

4,6-bis-\{1-[(4,6-dichloro-[1,3,5]triazine-2-yl)-hydrazone]-ethyl\}-benzene-1,3-diol $\quad\left(\mathrm{H}_{2}\right.$-BDTD) (Scheme 3). A solution of cyanuric chloride $(0.33 \mathrm{~g}, 0.176 \mathrm{mmol})$ in $20 \mathrm{~mL}$ dry thf was added drop-wise with stirring to a suspension of DAAD $(0.2 \mathrm{~g}, 0.088 \mathrm{mmol})$ in the same solvent and the reaction mixture was kept in an ice bath. The stirring was continued for $c a .3 \mathrm{~h}$. Initially a

Bull. Chem. Soc. Ethiop. 2009, 23(2) 
clear solution was obtained from which a yellow solid separated gradually. The product was filtered off and washed thoroughly with thf and diethyl ether and dried in open air. Yield $=0.37$ g $(80 \%)$.

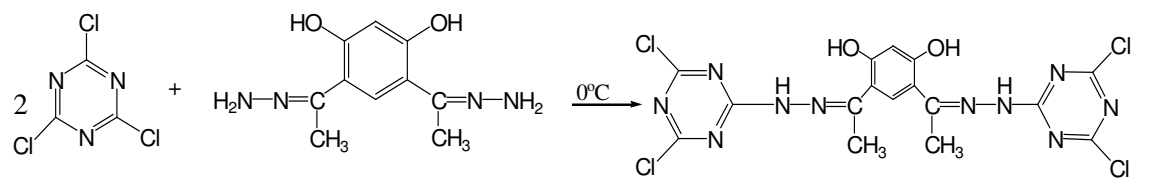

$$
\begin{array}{lll}
\text { Cyanuric chloride } \quad \text { DAAD } & \mathrm{H}_{2} \text {-BDTD }
\end{array}
$$

Scheme 3. Synthesis of $\mathrm{H}_{2}$-BDTD.

The analytical and IR spectral data of $\mathrm{H}_{2}$-BDTD are provided in Tables 1 and 2, respectively. The ${ }^{13} \mathrm{C}$ solid state NMR spectrum along with the assignment is presented in Figure 1.

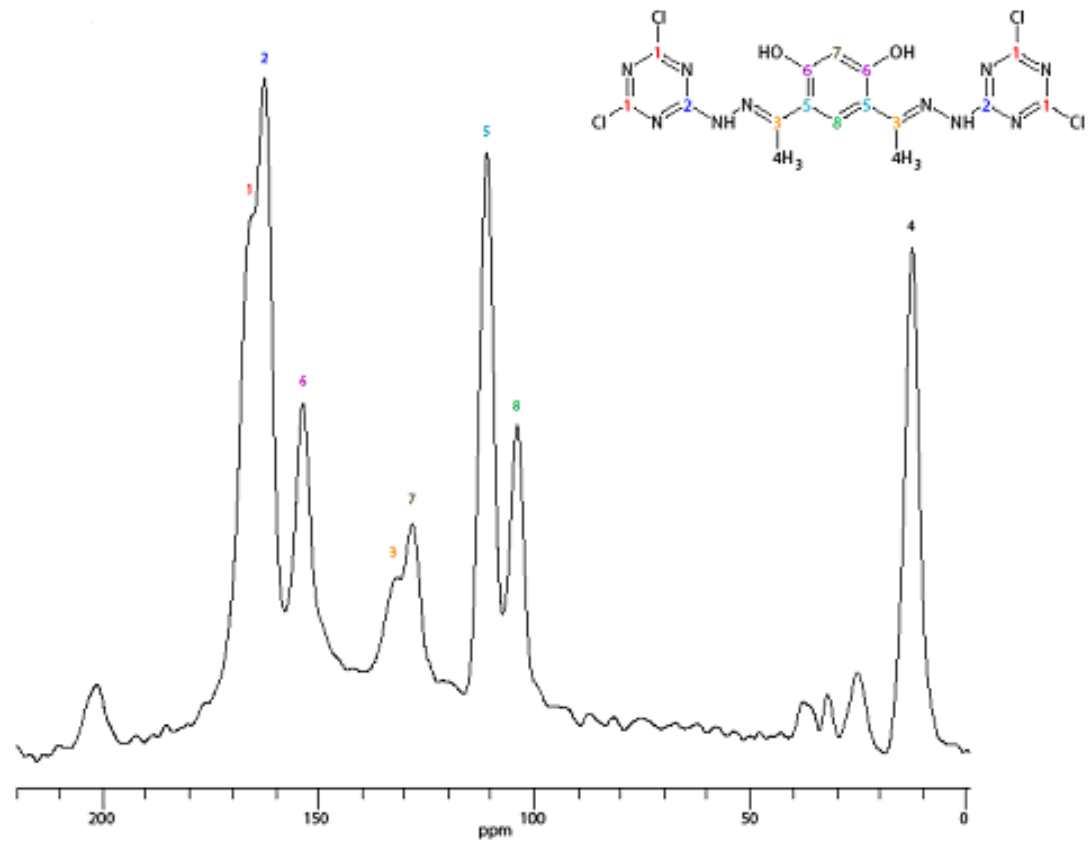

Figure $1 .{ }^{13} \mathrm{C}$ Solid-state NMR spectrum of $\mathrm{H}_{2}$-BDTD.

\section{Metal complexes}

The following general procedure was adopted. The mole ratio of ligand to metal chloride taken was $1: 2$. For this purpose $\mathrm{H}_{2}$-BDTD $(0.15 \mathrm{~g}, 0.29 \mathrm{mmol})$ was suspended in $50 \mathrm{~mL} \mathrm{1:1} \mathrm{mixture}$ of methanol and triethylamine and then $0.58 \mathrm{mmol}$ of metal salt, dissolved in the same solvent, was added to the suspension. The clear solution obtained was refluxed for $c a 10 \mathrm{~h}$. The product obtained was filtered off and washed thoroughly with methanol-triethylyamine mixture and

Bull. Chem. Soc. Ethiop. 2009, 23(2) 
diethyl ether. It was dried in the open air. The yields and some physical properties as well as the analytical data of the complexes are given in Table 1 .

Table 1. Physical properties and analytical data of and its metal complexes.

\begin{tabular}{|c|c|c|c|c|c|c|c|}
\hline \multirow[t]{2}{*}{ Compound } & \multirow[t]{2}{*}{ Color } & \multirow{2}{*}{$\begin{array}{l}\text { Yield } \\
(\%) / g\end{array}$} & \multicolumn{5}{|c|}{ Elemental analyses calcd. (found) \% } \\
\hline & & & $\mathrm{M}$ & $\mathrm{C}$ & $\mathrm{H}$ & $\mathrm{N}$ & $\mathrm{Cl}$ \\
\hline $\mathrm{C}_{16} \mathrm{H}_{12} \mathrm{~N}_{10} \mathrm{O}_{2} \mathrm{Cl}_{4}(\mathrm{~L})$ & Bright yellow, powder & $80 / 0.37$ & - & $\begin{array}{c}37.07 \\
(37.39)\end{array}$ & $\begin{array}{c}2.33 \\
(2.61)\end{array}$ & $\begin{array}{c}27.03 \\
(27.23)\end{array}$ & $\begin{array}{c}27.41 \\
(26.99)\end{array}$ \\
\hline $\mathrm{Co}_{2} \mathrm{LCl}_{2} \cdot 6 \mathrm{H}_{2} \mathrm{O} \cdot 2 \mathrm{NEt}_{3}$ & Dark green, crystalline & $74 / 0.22$ & $\begin{array}{c}11.61 \\
(11.38)\end{array}$ & $\begin{array}{c}33.11 \\
(33.45)\end{array}$ & $\begin{array}{c}5.12 \\
(4.87)\end{array}$ & $\begin{array}{c}16.55 \\
(16.25)\end{array}$ & $\begin{array}{c}20.65 \\
(20.99)\end{array}$ \\
\hline $\mathrm{Ni}_{2} \mathrm{LCl}_{2} \cdot 6 \mathrm{H}_{2} \mathrm{O} \cdot 2 \mathrm{NEt}_{3}$ & Brown, powder & $68 / 0.20$ & $\begin{array}{c}11.63 \\
(11.43)\end{array}$ & $\begin{array}{c}33.10 \\
(32.96)\end{array}$ & $\begin{array}{c}5.12 \\
(5.23)\end{array}$ & $\begin{array}{c}16.54 \\
(16.28)\end{array}$ & $\begin{array}{c}20.99 \\
(20.67)\end{array}$ \\
\hline $\mathrm{Cu}_{2} \mathrm{~L} \cdot(\mathrm{OH})_{2} \cdot 2 \mathrm{NEt}_{3}$ & Dark green, powder & $60 / 0.15$ & $\begin{array}{c}14.44 \\
(14.45)\end{array}$ & $\begin{array}{c}38.23 \\
(39.54)\end{array}$ & $\begin{array}{c}4.81 \\
(4.56)\end{array}$ & $\begin{array}{c}19.10 \\
(19.66)\end{array}$ & $\begin{array}{c}16.12 \\
(16.34)\end{array}$ \\
\hline $\mathrm{Zn}_{2} \mathrm{LCl}_{2} \cdot 6 \mathrm{H}_{2} \mathrm{O} \cdot 2 \mathrm{NEt}_{3}$ & Pale yellow, crystalline & $54 / 0.16$ & $\begin{array}{r}12.66 \\
(13.01) \\
\end{array}$ & $\begin{array}{c}31.69 \\
(31.35) \\
\end{array}$ & $\begin{array}{c}5.06 \\
(4.83) \\
\end{array}$ & $\begin{array}{c}16.56 \\
(16.33) \\
\end{array}$ & $\begin{array}{c}20.71 \\
(20.32) \\
\end{array}$ \\
\hline
\end{tabular}

\section{RESULTS AND DISCUSSION}

$\mathrm{H}_{2}$-BDTD and metal complexes are intensely colored and stable at room temperature. They do not melt but appear to decompose when heated above $300{ }^{\circ} \mathrm{C}$. They are insoluble in most common organic solvents. However, slight solubility was observed in $o$-dichlorobenzene. $\mathrm{H}_{2}$ BDTD also showed slight solubility in hot dmf.

\section{Elemental analysis}

The elemental analyses indicated a metal-to-ligand ratio of 2:1 in all the complexes. The analyses are consistent with the general formula $\mathrm{M}_{2} \mathrm{LCl}_{2} 6 \mathrm{H}_{2} \mathrm{O} 2 \mathrm{NEt}_{3}$ for the $\mathrm{Co}$ (II), $\mathrm{Ni}$ (II) and $\mathrm{Zn}$ (II) complexes and $\mathrm{M}_{2} \mathrm{~L}(\mathrm{OH})_{2} \cdot 2 \mathrm{NEt}_{3}\left(\mathrm{~L}=\mathrm{BDTD}_{2}{ }^{-}\right.$or $\mathrm{L}_{2}{ }^{-}$) for the $\mathrm{Cu}$ (II) complex .

\section{Conductivity measurements}

The conductivity studies (molar conductivity values were found to be lower than $20 \mathrm{~S}^{-1} \mathrm{~cm}^{2}$ $\mathrm{mol}^{-1}$ ) indicate the non-electrolytic nature of the complexes [14].

\section{Thermal analysis}

The decomposition of $\mathrm{H}_{2}$-BDTD was followed up to $590{ }^{\circ} \mathrm{C}$. An endotherm, which corresponds with about $6.1 \%$ weight loss until $125^{\circ} \mathrm{C}$ may be due to intramolecular elimination of two water molecules. The residue subsequently fragments through several exothermic processes as shown by the DSC curve. The total weight loss at $590{ }^{\circ} \mathrm{C}$ corresponds with $67.05 \%$. In the absence of related literature an approximation of the fragmentation pattern is presented in Scheme 4. 


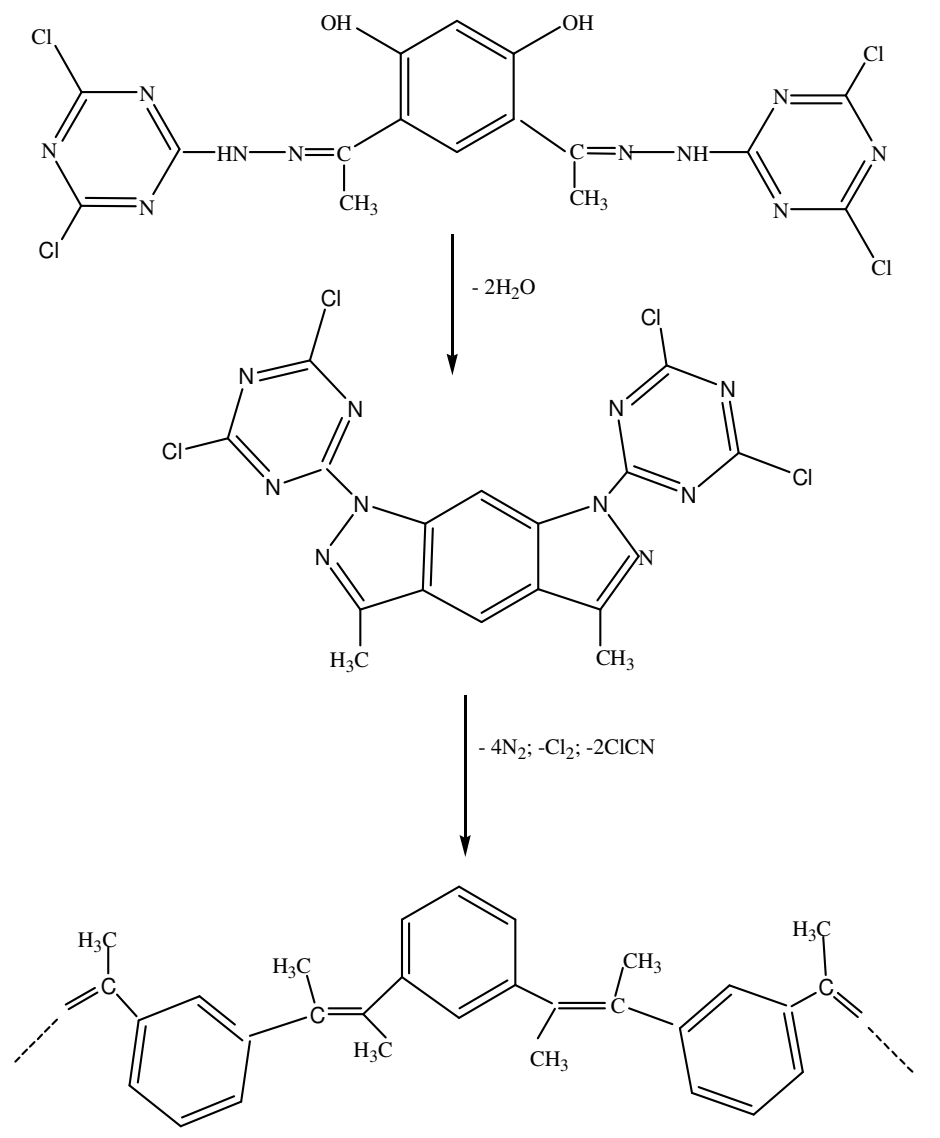

Scheme 4. Fragmentation of $\mathrm{H}_{2}$-BDTD proposed on the basis of DSC-TGA.

The TGA-DSC studies on the metal complexes reflect continuous decomposition up to 600 ${ }^{\circ} \mathrm{C}$ and the relative thermal stabilities of these complexes. In general, three overlapping endotherms were observed in the range of $80-300{ }^{\circ} \mathrm{C}$, which could be correlated with the elimination of water molecules (from lattice and coordinated sites) and coordinated lattice triethylamine molecules. The thermograms of $\mathrm{Co}$ (II) and $\mathrm{Ni}$ (II) complexes were better resolved than those of $\mathrm{Cu}$ (II) and $\mathrm{Zn}$ (II) complexes. In $\mathrm{Co}$ (II), Ni(II) and $\mathrm{Zn}$ (II) complexes the mass loss observations below $300{ }^{\circ} \mathrm{C}$ reasonably matched with about $30 \%$ weight loss, which accounted for six moles of water and two moles of triethylamine in each complex. However, the mass loss is about $25 \%$ in the $\mathrm{Cu}$ (II) complex, which also agrees with one mole of water and two moles of triethylamine. The residues obtained at $600{ }^{\circ} \mathrm{C}$ from $\mathrm{Co}(\mathrm{II})$ and $\mathrm{Ni}$ (II) complexes precisely matched with two moles of metal and a mass comparable to that of the free ligand at the same temperature, which may be correlated with the decomposition of the substituted triazine side chain. However, the residual masses of $\mathrm{Cu}$ (II) and $\mathrm{Zn}$ (II) complexes indicated that their decompositions did not stop at $600{ }^{\circ} \mathrm{C}$, as reflected by the shapes of the thermograms. These observations suggest that $\mathrm{Cu}$ (II) and $\mathrm{Zn}$ (II) complexes are thermally more stable than their $\mathrm{Co}(\mathrm{II})$ and $\mathrm{Ni}$ (II) analogues. Supporting thermogram traces are presented in Figures 2 and 3.

Bull. Chem. Soc. Ethiop. 2009, 23(2) 


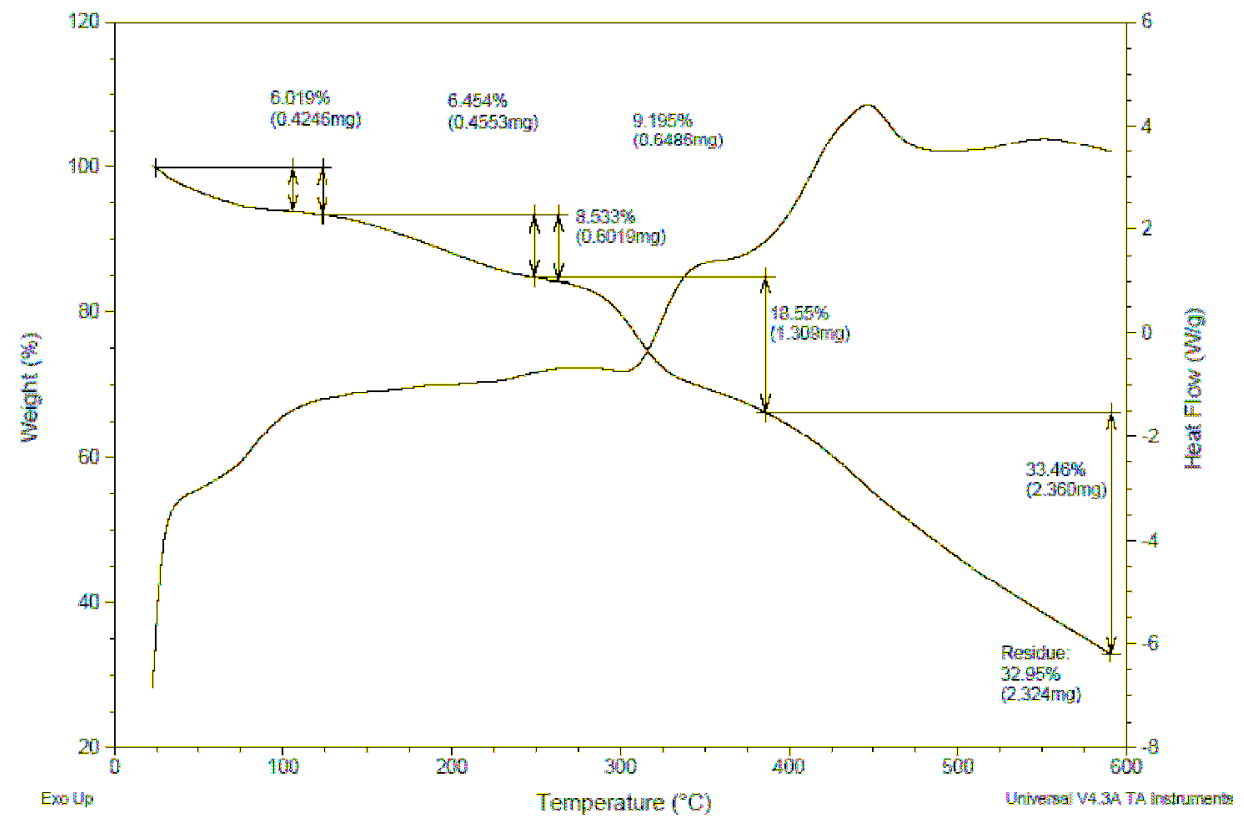

Figure 2. DSC-TGA of $\mathrm{H}_{2}$-BDTD.

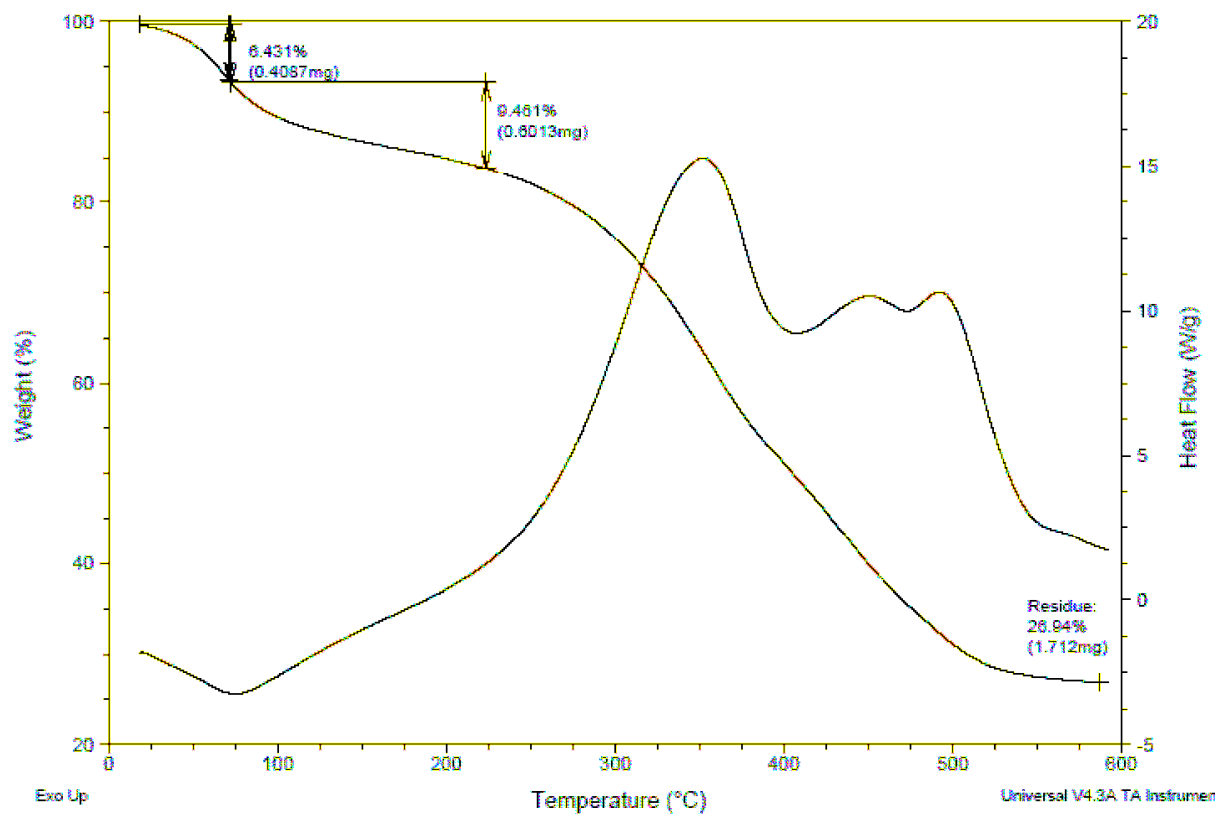

Figure 3. DSC-TGA of $\mathrm{Ni}^{2+}$ complex.

Bull. Chem. Soc. Ethiop. 2009, 23(2) 


\section{Mass spectrum}

The EI mass spectrum of $\mathrm{H}_{2}$-BDTDdoes not show the molecular ion peak. Instead fragmented ion of maximum $\mathrm{m} / z=205$ is recorded. This observation is indicative of instability of the compound under the experimental EI conditions.

IR spectra

The compound $\mathrm{H}_{2}-\mathrm{BDTD}$ exhibits a sharp split band at $3380 \mathrm{~cm}^{-1}$ assignable to $\mathrm{N}-\mathrm{H}$ stretching. The broad structure that appears in the regions $3400-2600 \mathrm{~cm}^{-1}$ is assignable to hydrogen bonded phenolic $\mathrm{OH}$. The band at $1619 \mathrm{~cm}^{-1}$ is due to the exocyclic $\mathrm{C}=\mathrm{N}$ stretching and $\mathrm{C}=\mathrm{C}$. Bands at $1551 \mathrm{~cm}^{-1}, 1511 \mathrm{~cm}^{-1}, 1374 \mathrm{~cm}^{-1}, 1324-1275 \mathrm{~cm}^{-1}$ and $850 \mathrm{~cm}^{-1}$ are characteristic of the triazine ring, in which the first two are stretching modes and the remaining are bending modes. The characteristic bands observed at $1243 \mathrm{~cm}^{-1}, 1176 \mathrm{~cm}^{-1}, 963 \mathrm{NN}$ stretching, NH rocking and $\mathrm{CCl}$ stretching, respectively.

The IR spectra of the metal complexes show features that can be correlated with complex formation. The characteristic stretching bands for the triazine ring show reduced multiplicities and negative shifts. The band corresponding to exocyclic $\mathrm{C}=\mathrm{N}$ shifts to a lower frequency, indicating the involvement of nitrogen in complexation. $[15,16]$. The involvement of the ring nitrogen of triazine in the coordination is further supported by negative shift of the multiplet bands in the region 1374-1275 $\mathrm{cm}^{-1}$. The shift to lower frequency in $v \mathrm{NN}$ in the spectra of all the complexes also confirmed the involvement of hydrazino nitrogen (corresponding to exocyclic azomethine function) in the coordination $[17,18]$. The presence of triethylamine was clearly indicated in the region of $1200 \mathrm{~cm}^{-1}$ in all the complexes. The rocking modes of coordinated triethylamine were observed in the region of $602-805 \mathrm{~cm}^{-1}$ as non-ligand bands $[19,20]$. The absence of the broad band extending up to $2600 \mathrm{~cm}^{-1}$ and the positive shift of CO stretching indicates the deprotonation of the phenolic group and complexation through phenoxide. However, the presence of lattice and coordinated water molecules and coordinated hydroxide ions in $\mathrm{Cu}$ (II) complex is indicated by the characteristic intense bands in the range of 3650-2800 $\mathrm{cm}^{-1}$. The wagging mode of coordinated water $[21,22]$ in the complexes fall in the same region as quoted for triethylamine. The non ligand bands observed in the region $500-425 \mathrm{~cm}^{-1}$ are attributed to $v(\mathrm{MO})$, and $v(\mathrm{MN})$. From the IR data of the metal complexes, it is concluded that the ligand behaves as a dibasic bis-NNO chelating system. Characteristic IR data are summarized in Table 2 .

Table 2. IR spectral data of the $\mathrm{H}_{2}$-BDTD and metal complexes.

\begin{tabular}{|l|l|l|l|l|l|}
\hline $\begin{array}{l}\text { Compound/ } \\
\text { Frequency }\end{array}$ & $\begin{array}{l}\mathrm{C}_{16} \mathrm{H}_{12} \mathrm{~N}_{10} \mathrm{O}_{2} \mathrm{Cl} \\
4\end{array}$ & $\mathrm{Co}_{2} \mathrm{LCl}_{2} \cdot 6 \mathrm{H}_{2} \mathrm{O} \cdot 2 \mathrm{NEt}_{3}$ & $\begin{array}{l}\mathrm{Ni}_{2} \mathrm{LCl}_{2} \cdot 6 \mathrm{H}_{2} \mathrm{O} \cdot \\
2 \mathrm{NEt}_{3}\end{array}$ & $\begin{array}{l}\mathrm{Cu}_{2} \mathrm{~L}(\mathrm{OH})_{2} \cdot \\
2 \mathrm{NEt}_{3}\end{array}$ & $\begin{array}{l}\mathrm{Zn}_{2} \mathrm{LCl}_{2} \cdot 6 \mathrm{H}_{2} \mathrm{O} \\
2 \mathrm{NEt}_{3}\end{array}$ \\
\hline$v \mathrm{NH}, \mathrm{OH}$ & $3400-2600 \mathrm{~b}$ & $3600-2950 \mathrm{~b}, \mathrm{~m}$ & $3650-2800 \mathrm{~b}, \mathrm{~m}$ & $3450-3050 \mathrm{~b}, \mathrm{~m}$ & $3500-3000 \mathrm{~b}, \mathrm{~m}$ \\
\hline$v \mathrm{C}=\mathrm{N}(\mathrm{exo})$ & $1619 \mathrm{vs}$ & $1570 \mathrm{vs}$ & $1588 \mathrm{vs}$ & $1576 \mathrm{vs}$ & $1587 \mathrm{vs}$ \\
\hline$v \mathrm{~N}-\mathrm{N}$ & $963 \mathrm{~m}$ & $885 \mathrm{~m}$ & $880 \mathrm{~m}$ & $879 \mathrm{~m}$ & $886 \mathrm{~m}$ \\
\hline$v \mathrm{C}=\mathrm{N}($ ring) & $1551 \mathrm{~s}, 1511 \mathrm{~s}$ & $1490 \mathrm{~s}$ & $1490 \mathrm{~s}$ & $1487 \mathrm{~s}$ & $1488 \mathrm{~s}$ \\
\hline$v \mathrm{C}-\mathrm{O}$ & $1243 \mathrm{~s}$ & $1268 \mathrm{~s}$ & $1268 \mathrm{~s}$ & $1272 \mathrm{~s}$ & $1268 \mathrm{~s}$ \\
\hline$\delta \mathrm{C}=\mathrm{N}($ ring) & $\begin{array}{l}1374 \mathrm{~s}, \\
1275-1324\end{array}$ & $1371 \mathrm{~s}$ & $1367 \mathrm{~s}$ & $1370 \mathrm{~s}$ & $1372 \mathrm{~s}$ \\
\hline$v N E t_{3}$ & ---- & $1198 \mathrm{~m}$ & $1192 \mathrm{~m}$ & $1195 \mathrm{~m}$ & $1199 \mathrm{~m}$ \\
\hline New bands & ---- & $\begin{array}{l}700 \mathrm{w}, 630 \mathrm{w} \\
500 \mathrm{w}, 450 \mathrm{w}\end{array}$ & $\begin{array}{l}685 \mathrm{w}, 600 \mathrm{w} \\
425 \mathrm{w}\end{array}$ & $\begin{array}{l}710 \mathrm{w}, 630 \mathrm{w} \\
450 \mathrm{w}\end{array}$ & $\begin{array}{l}686 \mathrm{w}, 734 \mathrm{w} \\
500 \mathrm{w}, 450 \mathrm{w}\end{array}$ \\
\hline
\end{tabular}


Magnetic susceptibility measurements

The magnetic moments calculated on the basis of the susceptibility measurements of the metal complexes at room temperature are given in the Table 3. The $\mathrm{Zn}$ (II) complex is diamagnetic, and the other complexes show subnormal magnetic moments. The subnormal values for $\mathrm{Cu}$ (II), $\mathrm{Ni}$ (II) and $\mathrm{Co}$ (II) complexes correspond to 1, 2, and 3 unpaired electrons, respectively. In the absence of cryomagnetic studies, the lower values of magnetic moments are explained by antiferromagnetic interaction via super-exchange (Figure 4) [23-25]. If the difference between the expected $\left(\mu_{\text {theor }}\right)$ and the observed $\left(\mu_{\text {obs }}\right)$ values is $\Delta_{\mu}, \Delta_{\mu} /$ ue, where ue is the number of unpaired electrons, may be taken as a measure of subnormality in magnetic moment. The subnormality at room temperature appears to be in the following order: $\mathrm{Ni}$ (II) $<\mathrm{Cu}$ (II) $<\mathrm{Co}$ (II). Spin pairing due to superexchange operates preferentially in the xy-plane. Thus, $\mathrm{Co}$ (II) with $\mathrm{d}^{7}$ configuration having more unpaired electrons in xy plane (one unpaired electron each in $\mathrm{d}_{\mathrm{xy}}$ and $\mathrm{d}_{\mathrm{x}}{ }^{2}{ }_{\mathrm{y}}{ }^{2}$ orbitals), reasonably shows a larger decrease in $\mu_{\mathrm{obs}}$. value for an octahedral complex in comparison with $\mathrm{Ni}$ (II) and $\mathrm{Cu}$ (II), which have only one unpaired electron in horizontal plane, i.e. in $\mathrm{d}_{\mathrm{x}}{ }^{2}{ }_{\mathrm{y}}{ }^{2}$ orbital. The less crowded square planar geometry of the $\mathrm{Cu}$ (II) complex gives more subnormality than the Ni compound.

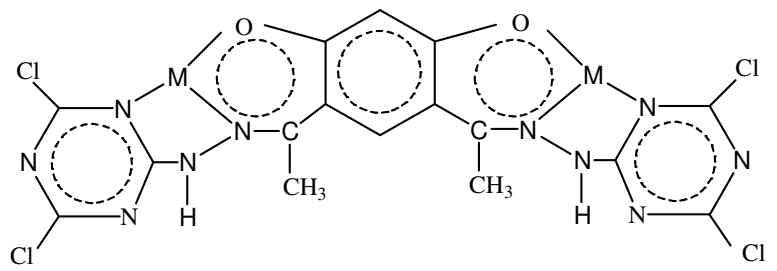

Figure 4. Extended conjugation depicting super-exchange phenomenon.

\section{Electronic spectra}

The electronic spectrum of $\mathrm{H}_{2}$-BDTD exhibited several bands corresponding to the proposed structure. Accordingly, the band at about $40,000 \mathrm{~cm}^{-1}$ was due to the $\pi \rightarrow \pi^{*}$ transitions of the substituted benzene ring [26]. The band at $38,023 \mathrm{~cm}^{-1}$ was attributed to the $\mathrm{n} \rightarrow \pi^{*}$ transition of the phenol [27], and that at $28,571 \mathrm{~cm}^{-1}$ was due to $\pi \rightarrow \pi^{*}$ and $\mathrm{n} \rightarrow \pi^{*}$ transitions of the triazine ring. The band at $27,777 \mathrm{~cm}^{-1}$ was assigned to the exocyclic azomethine chromophore. The spectra of metal complexes showed significant modifications, taken as an evidence for the participation of exocyclic and one-ring azomethine functions in coordination.

Table 3. Electronic spectral and magnetic moment data.

\begin{tabular}{|c|c|c|c|c|c|}
\hline Compound & $\lambda_{\max }\left(\mathrm{cm}^{-1}\right)$ & Transition & $\begin{array}{l}\mu_{\text {obs }} \text { (B.M.) } \\
\text { /metal ion } \\
\end{array}$ & $\begin{array}{l}\mu_{\text {theor }} \text { (B.M.) } \\
\text { /metal ion }\end{array}$ & $\Delta \mu / \mathrm{ue}^{*}$ \\
\hline $\mathrm{Co}_{2} \mathrm{LCl}_{2} \cdot 6 \mathrm{H}_{2} \mathrm{O} \cdot 2 \mathrm{NEt}_{3}$ & $\begin{array}{l}21,834,15,798 \text { and } \\
11,547\end{array}$ & $\begin{array}{l}{ }^{4} \mathrm{~T}_{1}(\mathrm{P}) \leftarrow{ }^{4} \mathrm{~T}_{1}(\mathrm{~F}),{ }^{4} \mathrm{~A}_{2} \leftarrow{ }^{4} \mathrm{~T}_{1}(\mathrm{~F}) \\
\text { and }{ }^{4} \mathrm{~T}_{2}(\mathrm{P}) \leftarrow{ }^{4} \mathrm{~T}_{1}(\mathrm{~F})\end{array}$ & 2.35 & 3.88 & 0.51 \\
\hline $\mathrm{Ni}_{2} \mathrm{LCl}_{2} \cdot 6 \mathrm{H}_{2} \mathrm{O} \cdot 2 \mathrm{NEt}_{3}$ & $\begin{array}{l}19,802,18,182 \text { and } \\
15,552\end{array}$ & $\begin{array}{l}{ }^{3} \mathrm{~T}_{1}(\mathrm{P}) \leftarrow{ }^{3} \mathrm{~A}_{2},{ }^{3} \mathrm{~T}_{1}(\mathrm{~F}) \leftarrow{ }^{3} \mathrm{~A}_{2} \text { and } \\
{ }^{3} \mathrm{~T}_{2} \leftarrow{ }^{3} \mathrm{~A}_{2}\end{array}$ & 2.63 & 2.83 & 0.1 \\
\hline $\mathrm{Cu}_{2} \mathrm{~L} \cdot \mathrm{H}_{2} \mathrm{O} \cdot 2 \mathrm{NEt}_{3}$ & $21,786-18,552$ & $\begin{array}{l}{ }^{2} \mathrm{~A}_{2} \leftarrow{ }^{2} \mathrm{~B}_{1}, \mathrm{E} \leftarrow{ }^{2} \mathrm{~B}_{1} \text { and } \\
{ }^{2} \mathrm{~B}_{2} \leftarrow{ }^{2} \mathrm{~B}_{1}\end{array}$ & 1.43 & 1.73 & 0.3 \\
\hline $\mathrm{Zn}_{2} \mathrm{LCl}_{2} \cdot 6 \mathrm{H}_{2} \mathrm{O} \cdot 2 \mathrm{NEt}_{3}$ & & -1.-- & Diamagnetic & & \\
\hline
\end{tabular}

Bull. Chem. Soc. Ethiop. 2009, 23(2) 
In the $\mathrm{Co}(\mathrm{II}), \mathrm{Ni}(\mathrm{II})$ and $\mathrm{Cu}(\mathrm{II})$ complexes additional features due to d-d transitions were observed. Assignments supporting octahedral stereochemistry for $\mathrm{Co}$ (II), $\mathrm{Ni}$ (II) and $\mathrm{Zn}$ (II) complexes and square planar geometry for $\mathrm{Cu}$ (II) complex [28-31] are given in Table 3 . However, the geometries may deviate from regularity in view of the unsymmetrical structure of the ligand.

\section{CONCLUSIONS}

A bis ONN- donor ligand, a novel combination of aromatic and N-heterocyclic systems was developed with a view to generate bimetallic complexes in which the metal ions could interact magnetically. The coordination of triethylamine, water and chloride ion in the $\mathrm{Co}(\mathrm{II}), \mathrm{Ni}(\mathrm{II})$ and $\mathrm{Zn}$ (II) complexes and hydroxide ions in $\mathrm{Cu}$ (II) complex besides the $\mathrm{L}^{2-}$ was proposed. Electronic spectra and magnetic data tentatively suggest octahedral geometry (Figure 5) for the Co(II) $\mathrm{Ni}$ (II) and $\mathrm{Zn}$ (II) complexes and square planar geometry (Figure 6) for the $\mathrm{Cu}$ (II) compound. The bimetallic paramagnetic complexes exhibited subnormal magnetic moments at RT.

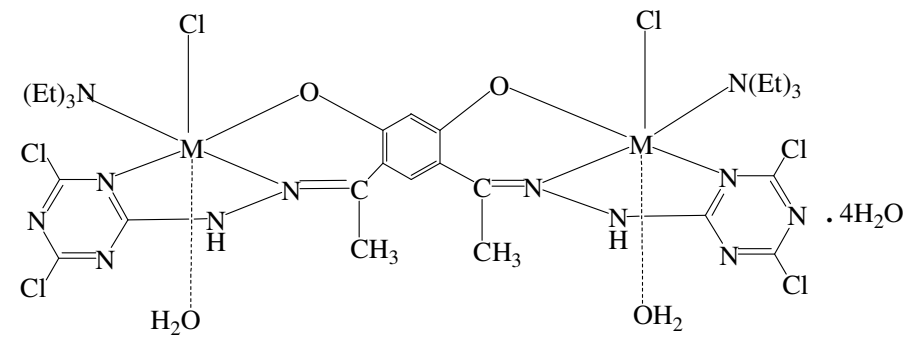

$\mathrm{M}=\mathrm{Co}(\mathrm{II}), \mathrm{Ni}(\mathrm{II}), \mathrm{Zn}(\mathrm{II})$

Figure 5. Proposed structure for $\mathrm{Co}(\mathrm{II}), \mathrm{Ni}(\mathrm{II})$ and $\mathrm{Zn}$ (II) complexes.

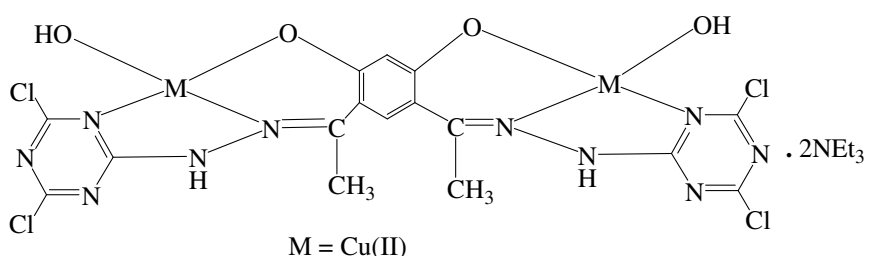

Figure 6. Proposed structure for $\mathrm{Cu}(\mathrm{II})$ complex.

\section{AKNOWLEDGEMENTS}

We thank the Indian Institute of Chemical Technology, Hyderabad, India for recording the MS spectrum of $\mathrm{H}_{2}$-BDTD, Dr. Jeremy Titman and Mr. Daniel Lee from the School of Chemistry, University of Nottingham, UK for recording solid state NMR and the Department of Chemistry, AAU for financial support. We also thank Prof. Wendimagegn Mammo, Department of Chemistry, AAU for useful discussions. 


\section{REFERENCES}

1. Halova-Lajoie, B.; Brumas, V.; Fiallo, M.L.; Berthon, G. J. Inorg. Biochem. 2006, 100, 362.

2. Isolda, C.M.; Juliana, P.M.; Nivaldo, L.S.; Antonio, S.M.; Jacqueline, A.T.; Heloisa, B. J. Braz. Chem. Soc. 2006, 17, 1571.

3. Antonini, I.; Polucci, P.; Magnamo, A.; Sparapani, S.; Martelli, S. J. Med. Chem. 2004, 21, 5244.

4. Peter, J.S. Molecules 2004, 9, 440.

5. Joule, J.A.; Mills, K. Heterocyclic Chemistry, 4th ed., Blackwell Publishing: Berlin; 2003, p 554.

6. Galán-Mascarós, J.-R.; Clemente-Juan, J.-M.; Dunbar, K.R. J. Chem. Soc., Dalton Trans. 2002, 2710.

7. Kebede, B.; Retta, N.; Raju, V.J.T.; Chebude, Y. Transition Met. Chem. 2006, 31, 19.

8. Gast, A.; Knusli, E.; Gysin, H. Experientia 1955, 11, 107.

9. Gast, A.; Knusli, E.; Gysin, H. Experientia 1956, 12, 146.

10. Ramon, J.; Mascaros, G.; Modesto, J.; Juan, C.; Dunbar, K.R. J. Chem. Soc., Dalton Trans. 2002, 2710.

11. Anjaneyulu, A.S.R.; Ramaprasad, A.V.; Reddy, S.K. Curr. Sci. 1979, 48, 300.

12. Rao, V.R.; Reddy, K.G.; Raju, V.J.T.; Seshaiah, U.V. Transition Met. Chem. 1993, 18, 58.

13. Shyamala B.S.; Raju, V.J.T. Synth. React. Inorg. Met-Org. Chem. 2003, 33, 63.

14. Costes, J.P.; Gareje, M.I.F. Transition Met. Chem. 1988, 13, 32.

15. Bellamy, L.J.; The Infrared Spectra of Complex Molecules, Champman and Hall: New York; 1980.

16. Aldrich, Catalog: Hand Book of Fine Chemicals, Aldrich: USA; 1988-1989.

17. Braibanti, A.; Dallavalle, F.; Pellinghelli, M.A.; Leporati, E. Inorg.Chem. 1968, 7, 1430.

18. Sared, L.E.L.; El-Toukli, A.; Wlka, N.; Iskander, D.V.; Iskander, M.F. Transition Met. Chem. 1980, 5, 293.

19. Jayashree, S.; Aravindakshan, K.K. Polyhedron 1993, 12, 1187.

20. Day, K.; Bandhyopadhyay, D. Indian J. Chem. 1992, 31A, 37.

21. Silverstein, M.; Webster, F.X. Spectrometric Identification of Organic Compounds, John Wiley and Sons: New York; 1998.

22. Nakamoto, K. Infrared and Raman Spectra of Inorganic and Coordination Compounds, John Wiley and Sons: New York; 1997.

23. Tamine, M.; Nogues, M.; Grenache, J.M. J. Phys: Condens. Mat. 2002, 14, 1029.

24. Singh, R. J. Phys. D: Phys, 1984, 17, 163.

25. Fernandez, M.I.; Oliva, J.M.; Armesto, X.L.; Canle, L.M.; Santaballa, A. Chem. Phys. Lett. 2006, 426, 290.

26. Bowder; Braden; Jones J. Chem. Soc. 1946, 948.

27. Alexandro, N.E.; Nicolaides, D.N. J. Chem. Soc. 1969, 2319.

28. Jorgenson, C.K. Absorption Spectra and Chemical Bonding in Complexes, Pergamon Press: Oxford; 1962, p 92.

29. Seetharamarao, T.; Reddy, K.L.; Swamy, S.J.; Lingaiah, P. Indian J. Chem. 1985, 24(A), 944.

30. Billing, D.E.; Vanderhil, A.E.; Adams, D.M.; Mans, D.M. J. Chem. Soc. (A) 1962, 922.

31. Labisbal, E.; Castineiras, A.; Brown, C.A.; West, D.X. Z. Naturforsch. 2001, 56b, 229. 